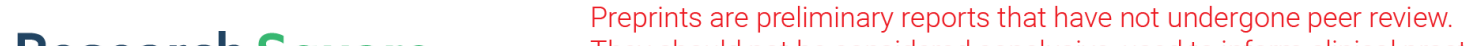 \\ They should not be considered conclusive, used to inform clinical practice, or referenced by the media as validated information. \\ Optimizing the Performance of $68 \mathrm{Ga}$ Labeled FSHR Ligand in Prostate Cancer Model by Means of Aprotinin
}

\section{Donghui Pan}

Jiangsu Institute of Nuclear Medicine

\section{Lizhen Wang}

Jiangsu Institute of Nuclear Medicine

\section{Xinyu Wang}

Jiangsu Institute of Nuclear Medicine

Junjie Yan

Jiangsu Institute of Nuclear Medicine

YuPing Xu ( $\nabla$ xuyuping@jsinm.org )

Jiangsu Institute of Nuclear Medicine

Min Yang

Jiangsu Institute of Nuclear Medicine

\section{Research Article}

Keywords: Radiolabeled FSH1, protease inhibitor, tumors, metabolism analyses, pharmacokinetic profile

Posted Date: September 17th, 2021

DOI: https://doi.org/10.21203/rs.3.rs-874882/v1

License: () (1) This work is licensed under a Creative Commons Attribution 4.0 International License.

Read Full License 


\section{Abstract}

Purpose. Radiolabeled FSH1 peptides are potential specific probes for FSHR imaging. However, moderate uptakes and fast washout from the tumors may limit its widespread use. In this study, ${ }^{68} \mathrm{Ga}$ labeled modified FSH1 analogs was prepared and the imaging properties were determined in the prostate cancer model with or without aprotinin.

Methods. NOTA-MAL-FSH4 was synthesized and labeled with ${ }^{68} \mathrm{Ga}$. The pharmacokinetic profile of the peptide after co-administration with aprotinin was determined through metabolism analyses and microPET imaging.

Results: ${ }^{68} \mathrm{Ga}$-NOTA-MAL-FSH4 was successfully prepared. The IC50 value of displacement ${ }^{68} \mathrm{Ga}-\mathrm{NOTA}-$ MAL-FSH4 with FSH1 was $139.4 \pm 1.16 \mathrm{nM}$. The PC-3 prostate tumor was visible after administration of the ${ }^{68} \mathrm{Ga}$ labeled tracer. In vitro RP-HPLC analysis revealed that the average percentage of intact peptide in the plasma, liver and tumor was $8.30,9.57$ and $7.06 \%$ respectively. In presence of aprotinin, the amounts of intact peptide increased to $34.32 \%, 20.63 \%$ and $15.39 \%$ in the counterparts respectively. MicroPET imaging showed that the uptakes of PC-3 tumors at 60 mins after co-administration of $100 \mu \mathrm{g}$, $200 \mu \mathrm{g}$ or $400 \mu \mathrm{g}$ enzyme inhibitors were $2.91 \pm 0.21 \% \mathrm{ID} / \mathrm{g}, 3.89 \pm 0.16 \% \mathrm{ID} / \mathrm{g}$ and $9.21 \pm 0.22 \% \mathrm{ID} / \mathrm{g}$ respectively.

Conclusion: With the aid of a serine protease inhibitor, the performance of the ${ }^{68} \mathrm{Ga}$ labeled peptide was optimized, which may benefit further clinical application.

\section{Introduction}

Follicle stimulating hormone receptor (FSHR) is a glycosylated transmembrane protein and plays an important role in reproductive processes through binding to the glycoprotein, FSH. [1] It was mainly located in the testicular sertoli cells and ovarian granulose cells with low levels in mammals.[2]

Recently, FSHR was observed to be overexpressed in numerous tumors such as prostate cancer, ovarian cancer, head and neck squamous cancer, etc. [3, 4]On the contrary, the receptor was absent in normal and non-malignant tissues. It was found that FSHR participated in promoting the growth of tumors. [5, 6]Animal studies showed that a DNA vaccine towards FSHR could efficiently delay the progression of FSHR positive tumors and increasing the immunity against the tumor. [7]Also, FSHR may play a specific role in neoangiogenesis since the percentage of FSHR positive vessels was significantly higher in the patients with kidney cancer responded to the treatment with sunitinib than those in the non-responsive group. [8]These features imply that FSHR might be an appealing target for tumor diagnosis and therapy. $[9,10]$ Development of specific ligands to the receptors may provide effective theranostic strategies against cancer for personalized treatment.

It was proved that the 33-53 region of $\mathrm{FSH} \beta$ chain, $\mathrm{FSH} 33-53$ peptide(denoted as $\mathrm{FSH} 1$ ), owns a strong binding affinity to FSHR and becomes an attractive vector for drug delivery to enhance the antitumor 
effect.[11, 12] For example, FSH1 peptide-conjugated gro-a siRNA-loaded polyethylene glycolpolyethylenimine nanoparticles orpaclitaxel nanoparticles can efficiently suppress the growth of ovarian cancers.[13] Besides, radiolabeled FSH1 analog might be a potential specific probe for FSHR imaging.

Previous studies revealed that ${ }^{18} \mathrm{FAl}$ labeled FSH1 peptides were specific FSHR probes and the tumors were visualized via a microPET scan. [14]To further improve the pharmacokinetic profile, a hydrophilic linker (GGGRDN) was introduced at the N-terminals of FSH1. [15]lt showed that the modification could decrease the abdomen radioactivity background. However, moderate uptakes and fast washout of the tracer ( $3 \% \mathrm{ID} / \mathrm{g}$ at $0.5 \mathrm{~h}$ post-injection and $\sim 1 \% \mathrm{ID} / \mathrm{g}$ at 2 hours postinjection) from the tumors may partially hamper their application.

Degradation of peptides by various proteases present in the plasma and digestive system may be a possible reason. The proteases decrease the metabolic stability of the peptides and affect their performance in molecular imaging. Enzyme inhibitors were proofed to increase metabolic stability and prolong tumor localization of the peptides. [16]After coinjection with the protease neutral endopeptidase, the percentage of intact radiopeptide, ${ }^{177}$ Lu-DOTA-GRP(13-27), in the mouse circulation was prolonged and the tumor uptakes were also increased nearly three times.[17]

Serine protease is found in eukaryotes, prokaryotes, archaea, and viruses. The enzyme cleaves peptide bonds through the nucleophilic amino acid, serine, at the active site. [18]Aprotinin (also named Trasylol) is a competitive serine protease inhibitor consisted of a single peptide chain with three disulfide bonds. It forms stable complexes with the serine protease including trypsin, chymotrypsin, plasmin as well as other related proteolytic enzymes, and blocks the active sites of enzymes. [19]Thus, we speculated that the tumor uptake of the radiolabeled FSH1 peptides might be enhanced via coadministration of aprotinin.

${ }^{68} \mathrm{Ga}$ is an attractive nuclide for PET imaging due to its simple availability by eluting the ${ }^{68} \mathrm{Ge} /{ }^{68} \mathrm{Ga}$ generator every 4 hours in the same day without an onsite cyclotron. Besides, ${ }^{68} \mathrm{Ga}$ is easily labeled to peptides by conjugating with macrocyclic chelators, and the labeling yields were higher than those of ${ }^{18} \mathrm{~F}$ labeled counterparts.[20-23]

In this study, a FSH1 analog, FSH4, was obtained by introducing a hydrophilic linker (GGGRDN) into FSH1 at C-terminals and conjugated with malemide-NOTA. The resulting peptides, NOTA-MAL-FSH4 was labeled with ${ }^{68} \mathrm{Ga}$. (Fig. 1). The properties for FSHR PET imaging with ${ }^{68} \mathrm{Ga}-\mathrm{NOTA}-\mathrm{MAL}-\mathrm{FSH} 4$ were firstly investigated in prostate cancer models. Also, the effect of aprotinin on the tumor imaging performance of the radiolabeled peptide was further evaluated.

\section{Materials And Methods}

General

FSH4 peptide (YTRDLVYKDPARPKIQKTCTFNDRGGG) and FSH1 peptide were obtained from Apeptide Co., Ltd. (Shanghai, China). Malemide-NOTA (denoted as MAL-NOTA) was purchased from CheMatech 
(Dijon, France). Aprotinin was bought from Sigma-Aldrich. $\left[{ }^{68} \mathrm{Ga}^{6} \mathrm{GaCl}_{3}\right.$ was obtained by eluting a ${ }^{68} \mathrm{Ge} /{ }^{68} \mathrm{Ga}$-generator (ITG, Germany) with $0.05 \mathrm{M}$ hydrochloric acid. All reagents were analytical grade and employed without further purification. HPLC systems for analysis and purification peptides were the same as the literature report. $[14,15,24]$ The animal experiments were performed according to the national regulations and approved by the animal welfare committee.

\section{NOTA Conjugation of Peptides}

FSH4 (3mg, $0.96 \mu \mathrm{mol})$ was added to a vial and followed by $3 \mathrm{ml}$ Malemide-NOTA $(0.5 \mathrm{mg}, 1,1 \mu \mathrm{mol})$ in $2 \mathrm{M}$ ammonium acetate solutions. Then the mixture was stirred at $40{ }^{\circ} \mathrm{C}$ overnight. After purification with HPLC, the desired product was collected and lyophilized as a white powder. The mass spectrum was determined using a high resolution LC-MS system(Waters, Milford, USA).

\section{Preparation of ${ }^{68}$ Ga-NOTA-MAL-FSH4}

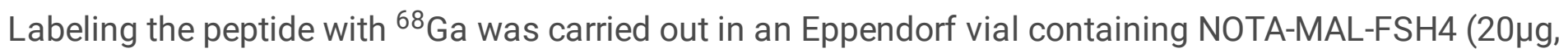
$6.7 \mathrm{nmol})$. Fresh $\left[{ }^{68} \mathrm{Ga}\right] \mathrm{GaCl}_{3}(185 \mathrm{MBq})$ eluate was added to the vial followed by $0.25 \mathrm{M}$ sodium acetate solutions. After incubating at $100^{\circ} \mathrm{C}$ for $10 \mathrm{~min}$, the complex was diluted with deionized water and then loaded into a Varian BOND ELUT C18 column. The labeled peptide was obtained after eluting the column with $200 \mu \mathrm{L} 10 \mathrm{mM} \mathrm{HCl}$ in ethanol. The product was reconstituted in saline and sterilized using a $0.22 \mu \mathrm{m}$ Millipore filter. Radiochemical purity was analyzed with HPLC.

\section{Cell lines and animal models}

PC-3 human prostate cancer cells were purchased from Cell Bank of Shanghai Institutes for Biological Sciences. The cells were cultured in DMEM (Gibco, USA) and supplemented with $10 \%(\mathrm{v} / \mathrm{v})$ fetal bovine serum and kept in a humidified atmosphere containing $5 \% \mathrm{CO}_{2}$ at $37^{\circ} \mathrm{C}$.

Male Balb/c nude mice (4 weeks old) were obtained from CAVENS Laboratory animal co.Itd, China. A suspension of $5 \times 10^{6} \mathrm{PC}-3$ cells in sterilized saline was subcutaneously injected into the right front flank of the mice. When the tumors developed proper sizes $\left(100-300 \mathrm{~mm}^{3}\right)$, the following animal experiments were performed.

\section{Cell Binding Assay}

PC-3 human prostate cancer cells $\left(2 \times 10^{5}\right.$ cells) were seeded in 6 wells plates and cultured at $37^{\circ} \mathrm{C}$ overnight. After washing with binding buffer (RPMI, $0.5 \%$ bovine serum albumin), ${ }^{68} \mathrm{Ga-NOTA-MAL-}$ FSH4 ( $37 \mathrm{KBq}$ ) and FSH1 peptide ranged from 0 to $5,000 \mathrm{nM}$ were added to each well. The medium was removed after incubation for 2 hours at $37^{\circ} \mathrm{C}$. After washing 3 times with PBS, the cells were lysed using $1 \mathrm{M} \mathrm{NaOH}$ and the radioactivity was determined in a $y$-counter (PerkinElmer). Inhibitory concentration of $50 \%(I C 50)$ values were calculated by GraphPadPrism software. Experiment was performed in triplicate. 
Mice bearing PC-3 tumors were sacrificed and the main organs (blood, liver, kidney and tumor) were collected. After centrifugation at $4^{\circ} \mathrm{C}$, plasma was obtained from the blood. Other organs were homogenized with ice PBS at $4{ }^{\circ} \mathrm{C}$. Each plasma or tissue homogenate was added $37 \mathrm{KBq}{ }^{68} \mathrm{Ga}-\mathrm{NOTA}$ MAL-FSH4 with or without $100 \mu \mathrm{g}$ aprotinin and incubated $30 \mathrm{~min}$ at $37^{\circ} \mathrm{C}$. Plasma and tissue homogenates were denatured with an equivalent volume of acetonitrile in centrifuge tubes. After vortexing, the mixture was centrifuged and the supernatant was separated and analyzed by HPLC.

\section{In vivo MicroPET imaging}

Mice ( $n=4$ per group) were injected with $200 \mu \mathrm{L} 3.7 \mathrm{MBq}{ }^{68} \mathrm{Ga}-\mathrm{NOTA}-\mathrm{MAL}-\mathrm{FSH} 4$ in saline via a tail vein. After anesthetized with isoflurane, the mice were performed PET imaging using a microPET scanner (Inveon, Siemens). At 30min, $60 \mathrm{~min}$ and 120min postinjection, static PET images were acquired. To investigate the effects of enzyme inhibition by aprotinin, $100 \mu \mathrm{L} 3.7 \mathrm{MBq}{ }^{68} \mathrm{Ga}-\mathrm{NOTA}-\mathrm{MAL}-\mathrm{FSH} 4$ together with $100 \mu \mathrm{L}$ aprotinin $(100 \mu \mathrm{g}, 200 \mu \mathrm{g}$ or $400 \mu \mathrm{g}$ respectively) in saline were injected into mice via a tail vein. Static PET images were acquired for $10 \mathrm{~min}$ at $30 \mathrm{~min}, 60 \mathrm{~min}$ and $120 \mathrm{~min}$ after injection. The quantification analysis of PET images was carried out according to the previous method. $[14,15,24]$

\section{Ex vivo biodistribution experiments}

Mice bearing PC-3 tumors were injected with about 740KBq radiolabeled peptides in the absence or presence of $400 \mu \mathrm{g}$ aprotinin and sacrificed at selected time points. Blood, tumor and major organs were collected and weighed. The radioactivity was measured by a $\gamma$-counter. Data were determined by the percentage injected dose per gram of tissue (\%ID/g). Blocking studies were performed through coadministration of excessive unlabeled FSH1 with the tracer.

Statistical analysis.

One-way analysis of variance (ANOVA) and Student'st test were used for statistical analysis of data. P values of $<0.05$ were considered to be statistically significant.

\section{Results:}

\section{Chemistry}

NOTA-MAL-FSH4 was achieved with yields of nearly 50\%. Analytical HPLC showed that the chemical purity was greater than $90 \%$. High resolution LC-MS system measured m/z 3524.9 for $[\mathrm{MH}]^{+}$, calculated molecular weight $3524.7\left(\mathrm{C}_{153} \mathrm{H}_{242} \mathrm{~N}_{46} \mathrm{O}_{48} \mathrm{~S}\right)$.

\section{Radiochemistry}


${ }^{68} \mathrm{Ga}-\mathrm{NOTA}-\mathrm{MAL}-\mathrm{FSH} 4$ was synthesized with a decay-corrected yield $92.1 \pm 1.8 \%$. A single peak was detected at about $14 \mathrm{~min}$ by radio-HPLC and the radiochemical purity was greater than $95 \%$ (Figure 2). The specific activity was calculated to be at least $30 \mathrm{GBq} / \mu \mathrm{mol}$.

\section{Cell Binding Assay}

The binding of ${ }^{68} \mathrm{Ga}$-NOTA-MAL-FSH4 to FSHR can be displaced by increasing amounts of unlabeled FSH1. (Figure 3). The IC50 value of displacement ${ }^{68} \mathrm{Ga}-\mathrm{NOTA}-\mathrm{MAL}-\mathrm{FSH} 4$ with FSH1 was determined to be $139.4 \pm 1.16 \mathrm{nM}$.

\section{In vitro metabolism analysis}

RP-HPLC analysis showed that the percentages of intact peptides remained in plasma, liver and tumor homogenates were $8.30 \%, 9.57 \%$ and $7.06 \%$ respectively. In the presence of aprotinin, the corresponding values were increased to $34.32 \%, 20.63 \%$ and $15.35 \%$ respectively. (Figure 4 ) No intact peptide was found in the kidney homogenates.

\section{In vivo MicroPET Imaging}

Representative decay-corrected coronal microPET images of mice bearing PC-3 tumors after administration of ${ }^{68} \mathrm{Ga}-\mathrm{NOTA}-\mathrm{MAL}-\mathrm{FSH} 4$ were shown in figure 5 . ROI analysis showed that the tumor uptakes of ${ }^{68} \mathrm{Ga}$-NOTA-MAL-FSH4 were $2.89 \pm 0.33 \% \mathrm{ID} / \mathrm{g}, 2.07 \pm 0.11 \% \mathrm{ID} / \mathrm{g}$ and $1.85 \pm 0.12 \% \mathrm{ID} / \mathrm{g}$ at 30,60 and $120 \mathrm{~min}$ p.i. respectively. Uptakes in kidney increased from $61.68 \pm 3.98 \% \mathrm{ID} / \mathrm{g}$ at $30 \mathrm{~min}$ p.i. to 81.86 $\pm 2.21 \% \mathrm{ID} / \mathrm{g}$ at $2 \mathrm{~h}$ p.i. Renal system may be the main excretion pathway of the radiolabeled peptide.

Consistent with the results of in vitro metabolism analysis results, visualization of PC-3 tumors was substantially improved by co-injection of aprotinin, as shown by the increased signal intensity in the tumors. After coadministration of $100 \mu \mathrm{g}, 200 \mu \mathrm{g}$ and $400 \mu \mathrm{g}$ aprotinin, the uptakes of PC-3 tumors were $2.91 \pm 0.21 \% \mathrm{ID} / \mathrm{g}, 3.89 \pm 0.16 \% \mathrm{ID} / \mathrm{g}$ and $9.21 \pm 0.22 \% \mathrm{ID} / \mathrm{g}$ respectively at $60 \mathrm{~min} \mathrm{p.i.} \mathrm{At} \mathrm{the} \mathrm{same} \mathrm{time,}$ tumor to muscle uptake ratios were $6.33 \pm 0.58,7.98 \pm 1.23$ and $13.15 \pm 1.16$ respectively.

\section{Ex vivo Biodistribution Experiments}

The data of the biodistribution experiments are listed in Table 1. Radioactivity accumulated in PC-3 tumors were $3.13 \pm 0.27 \% \mathrm{ID} / \mathrm{g}, 2.21 \pm 0.37 \% \mathrm{ID} / \mathrm{g}$ and $1.78 \pm 0.16 \% \mathrm{ID} / \mathrm{g}$ at 30,60 and $120 \mathrm{~min}$ postinjection respectively. The tumor to blood and tumor to muscle uptake ratios were $1.46 \pm 0.13,2.59 \pm 0.32,3.76 \pm 0.31$, and $4.05 \pm 0.37,6.29 \pm 0.67$ and $11.92 \pm 1.10$ at the same time points respectively. Except for kidney, uptakes of the tracer in normal organs were below $2 \% \mathrm{ID} / \mathrm{g}$ at $60 \mathrm{~min}$ after administration of ${ }^{68} \mathrm{Ga}$ labeled peptides. The levels of radioactivity accumulated in tumors significantly reduced to $0.51 \pm 0.13 \% \mathrm{ID} / \mathrm{g}$ at $1 \mathrm{~h}$ postinjection in the presence of excessive FSH1 peptide.

Treatment with aprotinin resulted in a profound increase in ${ }^{68} \mathrm{Ga}-\mathrm{NOTA}-\mathrm{MAL}-\mathrm{FSH} 4$ uptake in PC-3 tumors. In accordance with PET imaging, the tumor uptakes significantly increased to $7.81 \pm 0.62 \% \mathrm{ID} / \mathrm{g}$ at $60 \mathrm{mins}$ 
p.i. after treatment with $400 \mu \mathrm{g}$ aprotinin. Also, tumor to blood and tumor to muscle uptake ratios were raised to $8.13 \pm 0.76$ and $12.67 \pm 1.18$ respectively.

\section{Discussion}

Radiolabeled peptides are useful approaches for cancer diagnosis and therapy. [25, 26]A close relationship between FSHR and cancers suggested that it is a potential target of the disease. Although FSH1 analogs labeled with PET nuclides can specifically bind to FSHR, low tumor uptakes may decrease the diagnostic sensitivity. Previous showed that co-injection of the enzyme inhibitors could prolong the accelerated radioactivity of ${ }^{99 \mathrm{~m}} \mathrm{Tc}$ or ${ }^{111}$ In labeled peptides in tumors.[27] [28]To evaluate the feasibility of improving the performance of radiolabeled FSH1 peptides through the strategy, a ${ }^{68} \mathrm{Ga}$ labeled modified FSH1 peptide was synthesized and the imaging properties were determined in prostate cancer models with or without aprotinin.

${ }^{68} \mathrm{Ga}$-NOTA-MAL-FSH4, was successfully prepared in $20 \mathrm{~min}$ through solid-phase extraction with satisfactory radiochemical purity. The yields were identical to other ${ }^{68} \mathrm{Ga}$ labeled $\mathrm{FSH} 1$ peptide and significantly higher than those of ${ }^{18} \mathrm{FAl}$ labeled counterparts ( 50\%.) respectively.[14]

In vitro competing assay revealed that the IC50 value of ${ }^{68} \mathrm{Ga}-\mathrm{NOTA}-\mathrm{MAL}-\mathrm{FSH} 4$ towards FSHR was similar to those of ${ }^{68} \mathrm{Ga}-\mathrm{NOTA}-\mathrm{MAL}-\mathrm{FSH} 1(139.4 \pm 1.16 \mathrm{nM}$ vs $123.7 \pm 1.21 \mathrm{nM})$. [24] lt implied that the affinity of FSH4 to FSHR was not affected after introducing the hydrophilic linker to FSH1 peptides.

Consistent with the behaviors of other FSHR tracers, radioactivity accumulated higher in FSHR positive PC-3 xenografts than normal organs such as heart, brain, muscle and livers etc except kidneys after administration of ${ }^{68} \mathrm{Ga}-\mathrm{NOTA}-\mathrm{MAL}-\mathrm{FSH} 4$. It implies that ${ }^{68} \mathrm{Ga}-\mathrm{NOTA}-\mathrm{MAL}-\mathrm{FSH} 4$ is a candidate probe targeting FSHR. Preclinical studies revealed that tumor uptakes of the ${ }^{68} \mathrm{Ga}$ labeled modified FSH1 peptide was significantly higher than those of unmodified counterpart $(2.07 \pm 0.11 \% \mathrm{ID} / \mathrm{g}$ vs $1.26 \pm$ $0.06 \% \mathrm{ID} / \mathrm{g}, \mathrm{p}<0.05$ ) at $60 \mathrm{~min}$ postinjection respectively.[24] It means that hydrophilic linkers may benefit for enhancing the retention values of the peptide in tumors.

The stability of ${ }^{68} \mathrm{Ga}$-NOTA-MAL-FSH4 in main metabolism organs (blood, liver,kidney) and the tumor were firstly analyzed using in vitro assay. Many radioactive metabolites were observed in the tissue homogenates after incubation of the peptide. It implies that ${ }^{68} \mathrm{Ga}$ labeled peptide may be easily cleaved by enzymes. HPLC analysis confirmed that polar radioactive metabolites with a retention time of about 3 minutes were disappeared in presence of aprotinin. At the same time, the intact peptides in blood, tumor and liver were significantly increased nearly 4, 2 and 2 times respectively. It primarily suggested that serine proteases might be responsible for the in vivo degradation of $\mathrm{FSH} 1$ peptides. Aprotinin efficiently inhibited enzyme degradation and improved the stabilization of the peptide in tissues.

In agreement with in vitro stability data, aprotinin coinjection resulted in favorable improvement on the pharmacokinetic profile in vivo PET imaging. The tumor uptakes increased about 1.5, 2 and 4 times than 
control after coinjection of $100 \mu \mathrm{g}, 200 \mu \mathrm{g}$ and $400 \mu \mathrm{g}$ aprotinin at $60 \mathrm{~min}$ p.i.respectively. Ex vivo biodistribution experiments revealed that radioactivities accelerated in normal organs such as liver, spleen and stomach etc after co-administration of $400 \mu \mathrm{g}$ enzyme inhibitor was significantly higher than those of control. Although the detailed mechanism was not cleared, the uptake ratios between tumor and non-target organ were similar due to stronger uptakes in tumors. For example, tumor to liver and tumor to stomach were about 2 and 3 respectively in the absence or presence of aprotinin at $60 \mathrm{~min}$ p.i. It was also noted that tumor to blood and tumor to muscles ratios could significantly increase nearly 3 and 2 times through preventing degradation of ${ }^{68} \mathrm{Ga}$ labeled peptide using aprotinin. Thus, coadministration of $400 \mu \mathrm{g}$ aprotinin with ${ }^{68} \mathrm{Ga}$ labeled $\mathrm{FSH} 1$ analog could gain satisfactory performance of FSHR target PET imaging.

\section{Conclusion:}

In summary, a ${ }^{68} \mathrm{Ga}$ labeled FSH1 analogs, ${ }^{68} \mathrm{Ga}-\mathrm{NOTA}-\mathrm{MAL}-\mathrm{FSH} 4$, was successfully prepared. Preclinical data indicate that the tracer is potential for non-invasive visualization of FSHR expression. Coadministration of aprotinin significantly enhanced the stability of ${ }^{68} \mathrm{Ga}$ labeled peptide, which promotes the profile of tumor targeting.

\section{Declarations}

Ackowledgement:

This work was partially supported by National Natural Science Foundation (22075114,31971316), Jiangsu Provincial Natural Science Foundation (BK20192005『BRA2019105), Jiangsu talent projects (LGY2017088,WSN-082),Jiangsu Provincial Commission of Health and Family Planning Fundation \QNRC2016628®,Wuxi Science Foundation(N20192014).

Competing interests

The authors declare that they have no conflict of interest.

\section{References}

1. Sun D, Bai M, Jiang Y, Hu M, Wu S, Zheng W et al (2020) Roles of follicle stimulating hormone and its receptor in human metabolic diseases and cancer. Am J Transl Res 12:3116-3132

2. Panza S, Giordano F, De Rose D, Panno ML, De Amicis F, Santoro M et al. FSH-R Human Early Male Genital Tract, Testicular Tumors and Sperm: Its Involvement in Testicular Disorders. Life (Basel). 2020;10

3. Radu A, Pichon C, Camparo P, Antoine M, Allory Y, Couvelard A et al (2010) Expression of folliclestimulating hormone receptor in tumor blood vessels. N Engl J Med 363:1621-1630 
4. Olejar T, Vetvicka D, Boucek J, Zabrodsky M, Benes J, Kabesova M et al (2020) The FSHR Expression in Head and Neck Squamous Cell Cancer. A Pilot Immunohistochemical Study. Anticancer Res 40:349-356

5. Oduwole 0O, Poliandri A, Okolo A, Rawson P, Doroszko M, Chrusciel M et al (2021) Folliclestimulating hormone promotes growth of human prostate cancer cell line-derived tumor xenografts. FASEB J 35:e21464

6. Song K, Dai L, Long X, Wang W, Di W (2020) Follicle-stimulating hormone promotes the proliferation of epithelial ovarian cancer cells by activating sphingosine kinase. Sci Rep 10:13834

7. Perales-Puchalt A, Wojtak K, Duperret EK, Yang X, Slager AM, Yan J et al (2019) Engineered DNA Vaccination against Follicle-Stimulating Hormone Receptor Delays Ovarian Cancer Progression in Animal Models. Mol Ther 27:314-325

8. Siraj MA, Pichon C, Radu A, Ghinea N (2012) Endothelial follicle stimulating hormone receptor in primary kidney cancer correlates with subsequent response to sunitinib. J Cell Mol Med 16:20102016

9. Ghinea N. Vascular Endothelial FSH (2018) Receptor, a Target of Interest for Cancer Therapy. Endocrinology 159:3268-3274

10. Ingels A, Leguerney I, Cournède PH, Irani J, Ferlicot S, Sébrié C et al (2020) Ultrasound Molecular Imaging of Renal Cell Carcinoma: VEGFR targeted therapy monitored with VEGFR1 and FSHR targeted microbubbles. Sci Rep 10:7308

11. Agris PF, Guenther RH, Sierzputowska-Gracz H, Easter L, Smith W, Hardin CC et al (1992) Solution structure of a synthetic peptide corresponding to a receptor binding region of FSH (hFSH-beta 3353). J Protein Chem 11:495-507

12. Zhang M, Liu Q, Zhang M, Cao C, Liu X, Zhang M et al (2020) Enhanced antitumor effects of folliclestimulating hormone receptor-mediated hexokinase-2 depletion on ovarian cancer mediated by a shift in glucose metabolism. J Nanobiotechnology 18:161

13. Hong S, Zhang X, Chen J, Zhou J, Zheng Y, Xu C (2013) Targeted gene silencing using a folliclestimulating hormone peptide-conjugated nanoparticle system improves its specificity and efficacy in ovarian clear cell carcinoma in vitro. J Ovarian Res 6:80

14. Xu Y, Pan D, Zhu C, Xu Q, Wang L, Chen F et al (2014) Pilot study of a novel (18)F-labeled FSHR probe for tumor imaging. Mol Imaging Biol 16:578-585

15. Zhu C, Xu Q, Pan D, Xu Y, Liu P, Yang R et al (2016) Prostate cancer imaging of FSHR antagonist modified with a hydrophilic linker. Contrast Media Mol Imaging 11:99-105. doi:10.1002/cmmi.1662

16. Casas-Godoy L, Sandoval G (2016) Proteases and their Inhibitors: From Basic to High Throughput Screening. Comb Chem High Throughput Screen 19:636-643

17. Nock BA, Maina T, Krenning EP, de Jong M (2014) "To serve and protect": enzyme inhibitors as radiopeptide escorts promote tumor targeting. J Nucl Med 55:121-127

18. Hedstrom L (2002) Serine protease mechanism and specificity. Chem Rev 102:4501-4524 
19. Briquez PS, Lorentz KM, Larsson HM, Frey P, Hubbell JA (2017) Human Kunitz-type protease inhibitor engineered for enhanced matrix retention extends longevity of fibrin biomaterials. Biomaterials 135:1-9

20. Meyer C, Dahlbom M, Lindner T, Vauclin S, Mona C, Slavik R et al (2020) Radiation Dosimetry and Biodistribution of (68)Ga-FAPI-46 PET Imaging in Cancer Patients. J Nucl Med 61:1171-1177

21. Wang XY, Wang Y, Wu Q, Liu JJ, Liu Y, Pan DH et al. Feasibility study of (68)Ga-labeled CAR T cells for in vivo tracking using micro-positron emission tomography imaging. Acta Pharmacol Sin. 2020

22. Yan J, Lu Y, Chen G, Yang M, Gu Z (2018) Advances in liquid metals for biomedical applications. Chem Soc Rev 47:2518-2533

23. Zhou N, Liu C, Guo X, Xu Y, Gong J, Qi C et al (2021) Impact of (68)Ga-NOTA-MAL-MZHER2 PET imaging in advanced gastric cancer patients and therapeutic response monitoring. Eur $\mathrm{J}$ Nucl Med Mol Imaging 48:161-175

24. Pan D, Liu G, Xu Y, Wang Y, Yue Y, Wang L et al (2017) PET Imaging of FSHR Expression in Tumors with (68)Ga-Labeled FSH1 Peptide. Contrast Media Mol Imaging 2017:2674502

25. Mikulová MB, Mikuš P. Advances in Development of Radiometal Labeled Amino Acid-Based Compounds for Cancer Imaging and Diagnostics. Pharmaceuticals (Basel). 2021;14

26. Mohtavinejad N, Shafiee Ardestani M, Khalaj A, Pormohammad A, Najafı R, Bitarafan-Rajabi A et al (2020) Application of radiolabeled peptides in tumor imaging and therapy. Life Sci 258:118206

27. Kanellopoulos P, Nock BA, Krenning EP, Maina T. Optimizing the Profile of [(99m)Tc]Tc-NT(7-13) Tracers in Pancreatic Cancer Models by Means of Protease Inhibitors. Int J Mol Sci. 2020;21 28. Kanellopoulos P, Kaloudi A, Jong M, Krenning EP, Nock BA, Maina T. Key-Protease Inhibition Regimens Promote Tumor Targeting of Neurotensin Radioligands. Pharmaceutics. 2020;12

\section{Tables}

Table 1 Biodistribution of ${ }^{68} \mathrm{Ga}-\mathrm{NOTA}-\mathrm{MAL}-\mathrm{FSH} 4$ in mice bearing PC-3 xenografts in the absence or presence of aprotinin respectively. 


\begin{tabular}{|llllll|}
\hline & Control & & & & $400 \mu g$ Aprotinin \\
\hline Organs & $30 \mathrm{~min}$ & $60 \mathrm{~min}$ & $120 \mathrm{~min}$ & $60 \mathrm{~min}$ block & $60 \mathrm{~min}$ \\
\hline blood & $2.22 \pm 0.21$ & $0.86 \pm 0.15$ & $0.61 \pm 0.07$ & $1.13 \pm 0.55$ & $2.12 \pm 0.47$ \\
\hline brain & $0.11 \pm 0.02$ & $0.10 \pm 0.01$ & $0.02 \pm 0.01$ & $0.07 \pm 0.01$ & $0.22 \pm 0.08$ \\
\hline heart & $0.81 \pm 0.11$ & $0.50 \pm 0.16$ & $0.18 \pm 0.02$ & $0.39 \pm 0.10$ & $1.65 \pm 0.35$ \\
\hline liver & $1.56 \pm 0.13$ & $0.78 \pm 0.20$ & $0.41 \pm 0.24$ & $1.28 \pm 0.26$ & $2.98 \pm 0.70$ \\
\hline spleen & $1.18 \pm 0.13$ & $0.71 \pm 0.13$ & $0.47 \pm 0.11$ & $0.81 \pm 0.12$ & $2.29 \pm 0.27$ \\
\hline lung & $1.38 \pm 0.18$ & $0.45 \pm 0.07$ & $0.39 \pm 0.02$ & $0.66 \pm 0.13$ & $1.82 \pm 0.18$ \\
\hline kidney & $96.09 \pm 8.17$ & $97.03 \pm 9.07$ & $85.23 \pm 7.69$ & $78.08 \pm 6.63$ & $62.84 \pm 8.72$ \\
\hline stomach & $1.34 \pm 0.77$ & $0.85 \pm 0.07$ & $0.71 \pm 0.09$ & $1.16 \pm 0.15$ & $2.42 \pm 0.49$ \\
\hline intestine & $0.53 \pm 0.10$ & $0.45 \pm 0.15$ & $0.31 \pm 0.04$ & $0.47 \pm 0.12$ & $1.98 \pm 0.39$ \\
\hline muscle & $0.73 \pm 0.09$ & $0.43 \pm 0.08$ & $0.18 \pm 0.06$ & $0.45 \pm 0.05$ & $0.65 \pm 0.08$ \\
\hline pancreas & $0.54 \pm 0.09$ & $0.36 \pm 0.04$ & $0.21 \pm 0.03$ & $0.48 \pm 0.09$ & $0.93 \pm 0.15$ \\
\hline bone & $0.73 \pm 0.03$ & $0.62 \pm 0.09$ & $0.38 \pm 0.12$ & $0.78 \pm 0.08$ & $0.75 \pm 0.08$ \\
\hline tumor & $3.13 \pm 0.27$ & $2.21 \pm 0.37$ & $1.78 \pm 0.16$ & $0.51 \pm 0.13$ & $7.81 \pm 0.62$ \\
\hline Ratio of tumor to & & & & & \\
\hline blood & $1.46 \pm 0.13$ & $2.59 \pm 0.32$ & $3.76 \pm 0.31$ & $0.75 \pm 0.18$ & $8.13 \pm 0.76$ \\
\hline muscle & $4.05 \pm 0.37$ & $6.29 \pm 0.57$ & $11.92 \pm 1.10$ & $1.13 \pm 0.29$ & $12.67 \pm 1.18$ \\
\hline
\end{tabular}

\section{Figures}


Tyr-Thr-Arg-Asp-Leu-Val-Tyr-Lys-Asp-Pro-Ala-Arg-Pro-Lys-Ile-Gln-Lys-Thr-NH

NOTA-MAL-FSH4

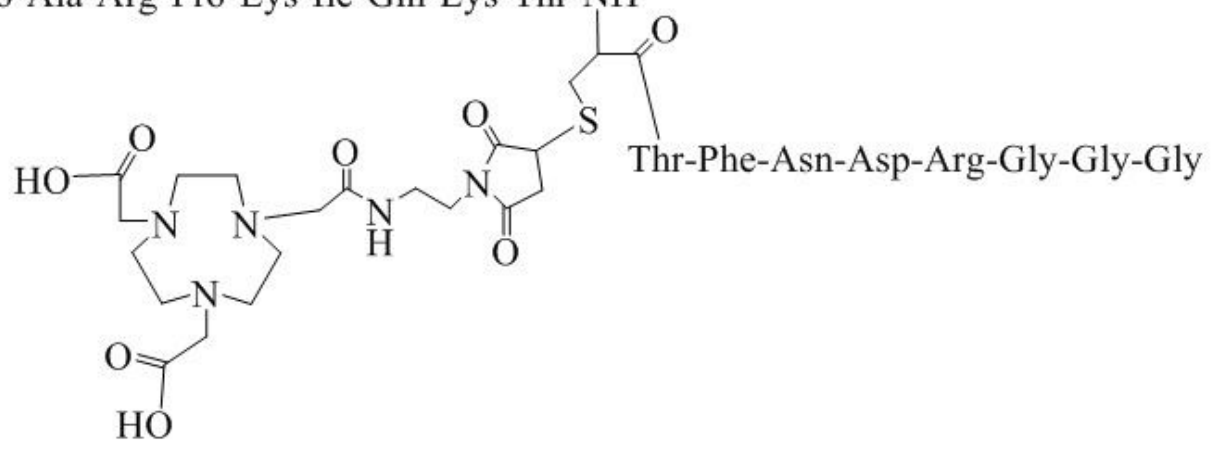

Tyr-Thr-Arg-Asp-Leu-Val-Tyr-Lys-Asp-Pro-Ala-Arg-Pro-Lys-Ile-Gln-Lys-Thr-NH

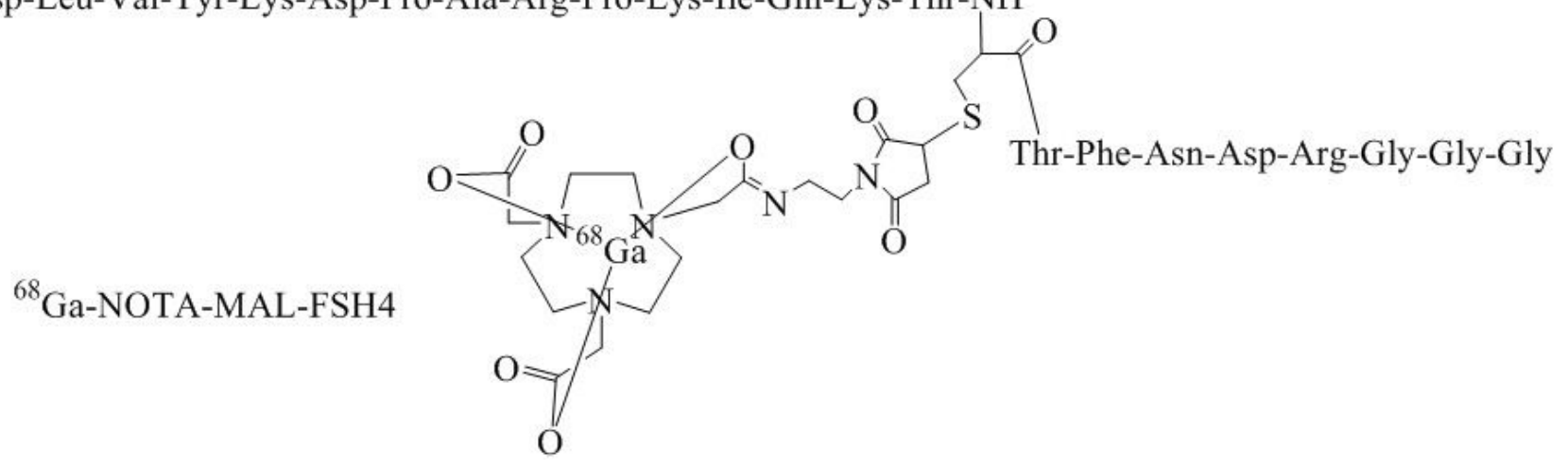

\section{Figure 1}

Schematic representation for preparing 68Ga- NOTA-MAL-FSH4.

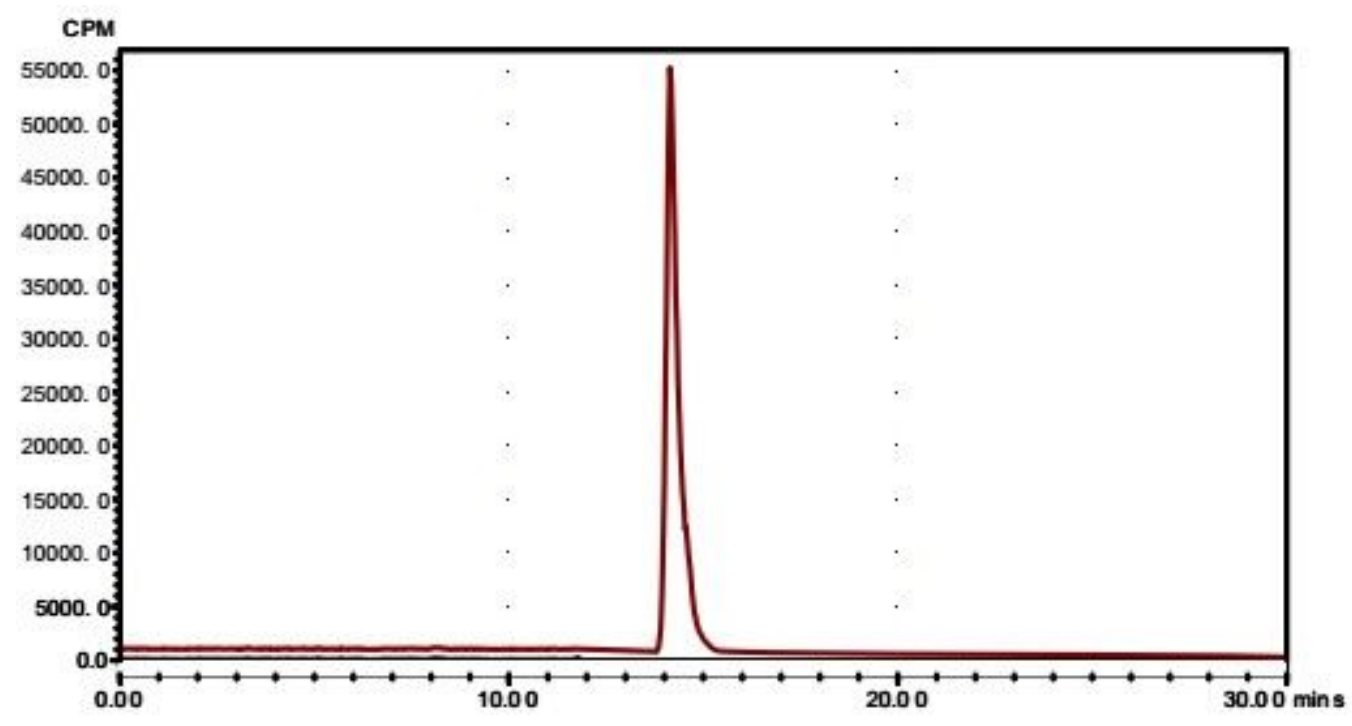

Figure 2 
RadioHPLC chromatograms of 68Ga- NOTA-MAL-FSH4.

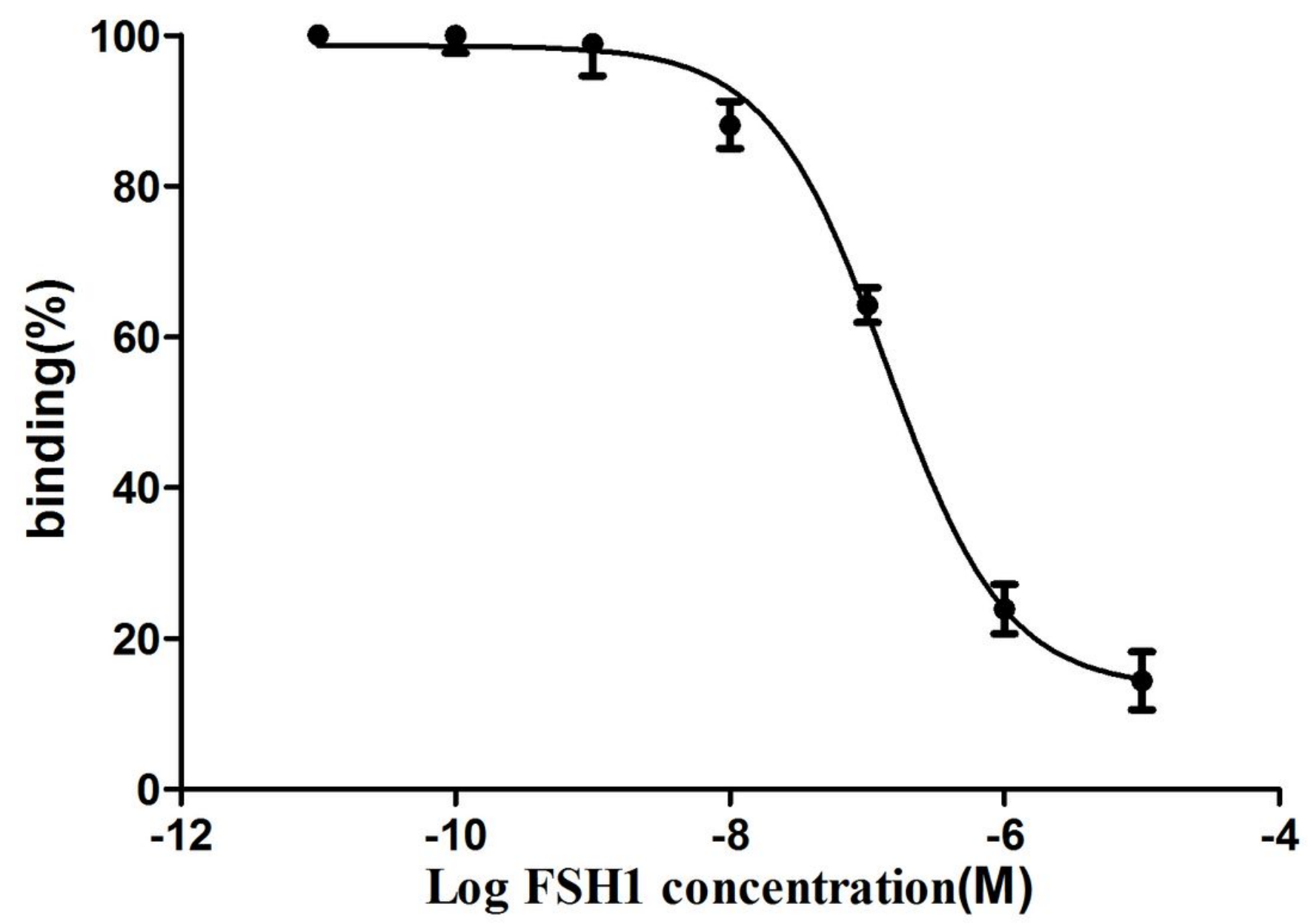

Figure 3

Competition of specific bindings of 68Ga-NOTA-MAL-FSH4 with FSH1. 

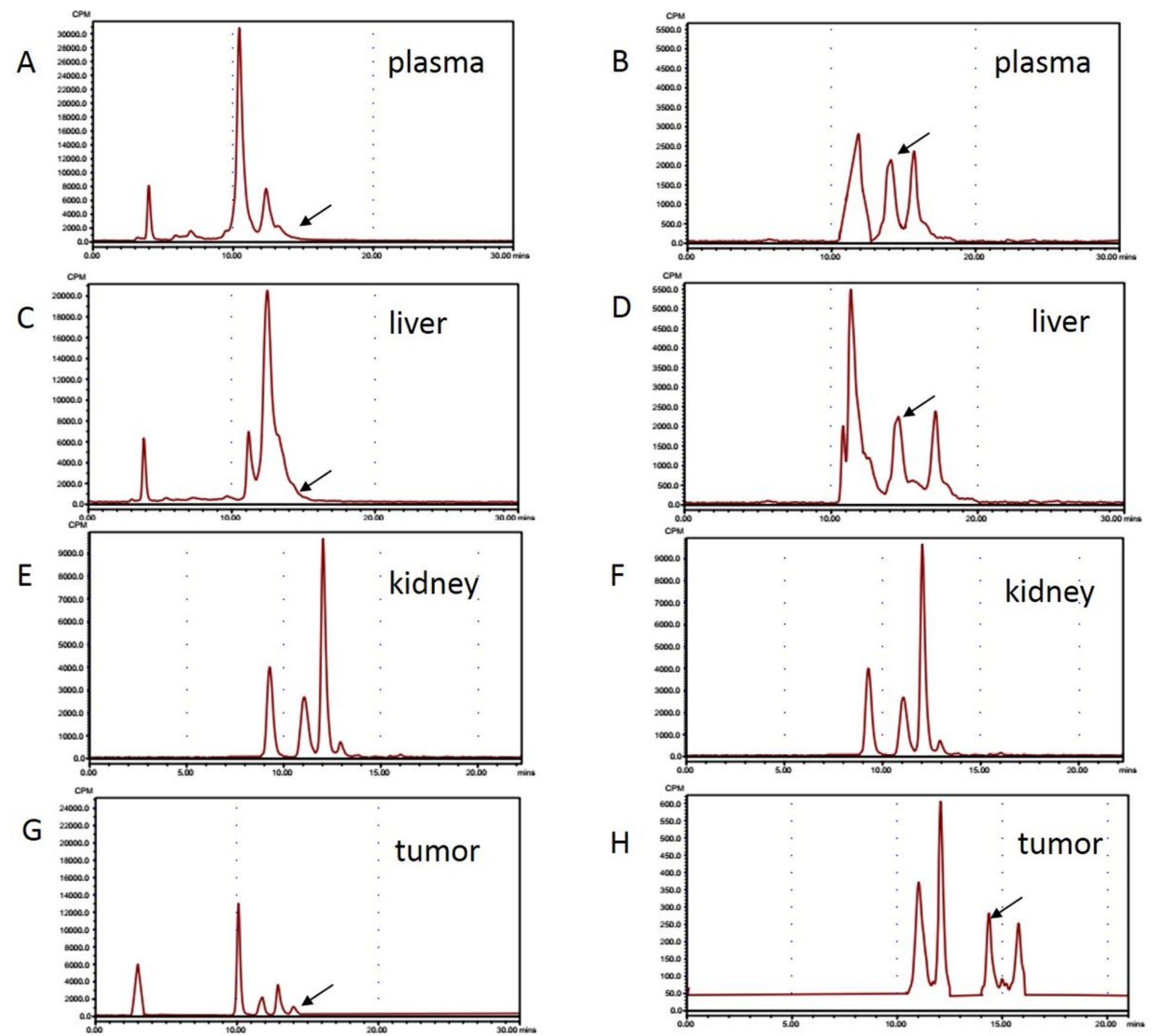

Figure 4

In vitro RP-HPLC analysis radiochromatogram of plasma, liver, kidney and PC-3 tumors after incubation with $68 \mathrm{Ga}-\mathrm{NOTA}-\mathrm{MAL}-\mathrm{FSH} 4$ in the absence $(\mathrm{A}, \mathrm{C}, \mathrm{E}, \mathrm{G})$ or presence of the aprotinin $(\mathrm{B}, \mathrm{D}, \mathrm{F}, \mathrm{H})$ respectively. The arrows indicate intact radiolabeled peptide. 


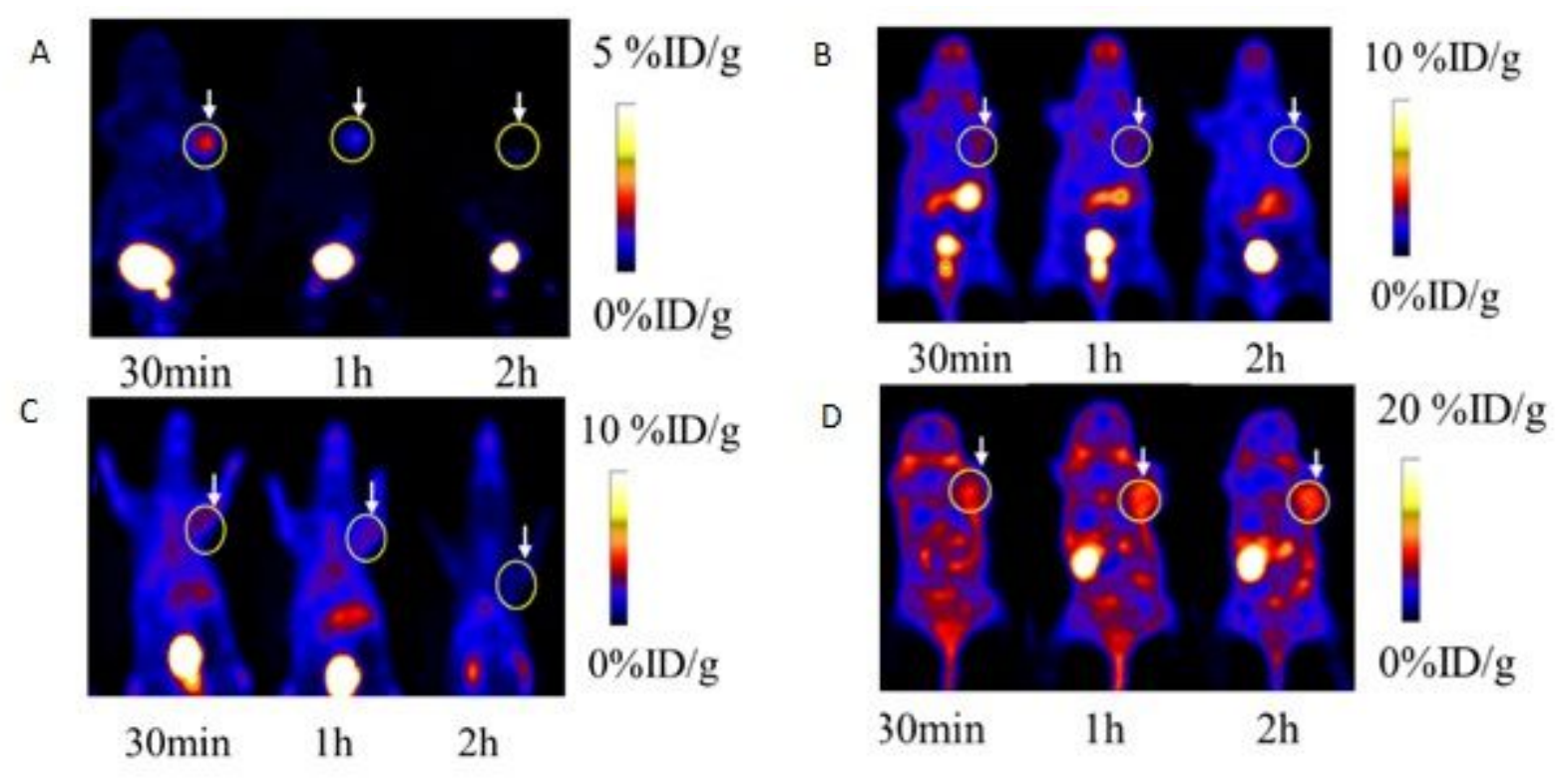

\section{Figure 5}

Decay-corrected whole-body PET images of mice bearing PC-3 xenografts after injection of 68Ga-NOTAMAL-FSH4 with the absence (A) or presence of $100 \mu \mathrm{g}(\mathrm{B}), 200 \mu \mathrm{g}(\mathrm{C})$ and $400 \mu \mathrm{g}(\mathrm{D})$ aprotinin respectively. Tumors are indicated by arrows. 

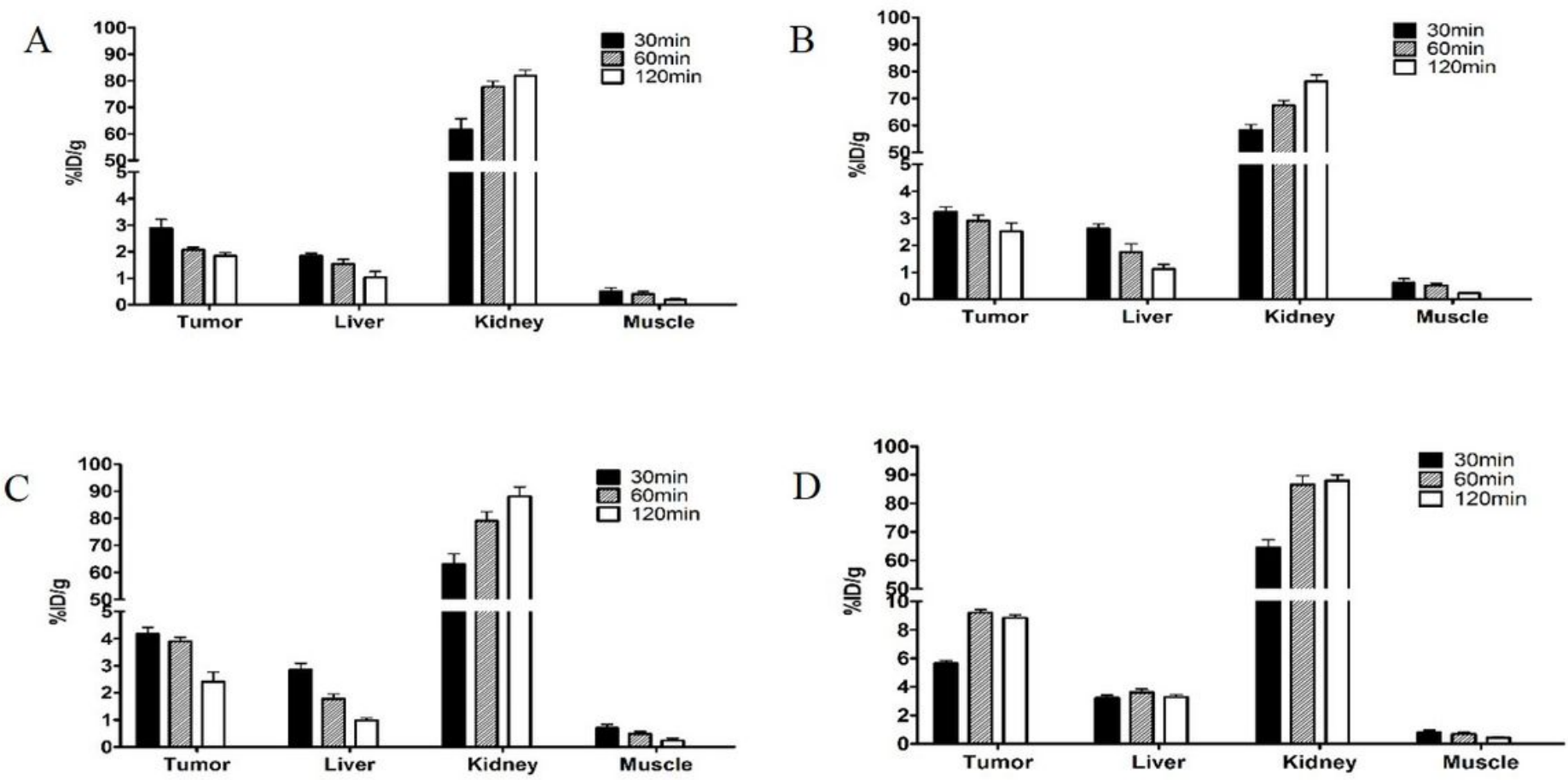

$\mathrm{E}$

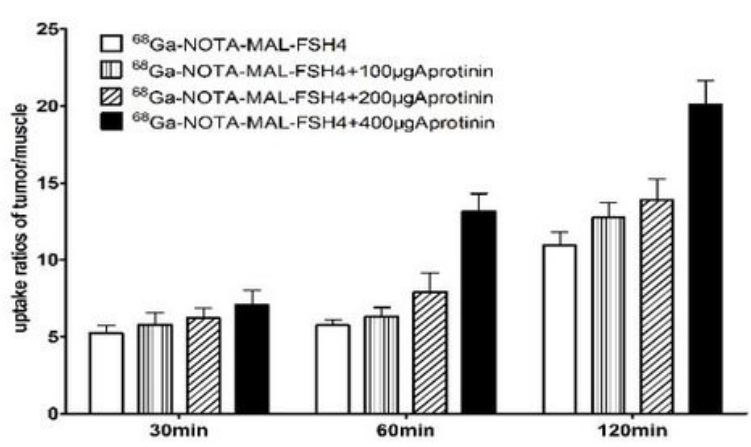

Figure 6

ROI analysis of $68 \mathrm{Ga}-\mathrm{NOTA}-\mathrm{MAL}-\mathrm{FSH} 4$ in PC-3 xenografts models in absence (A) or presence of $100 \mu \mathrm{g}$

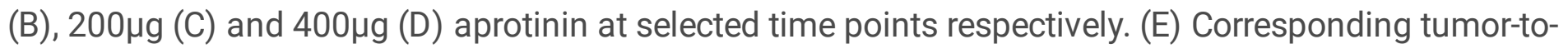
organ ratios for $68 \mathrm{Ga}-\mathrm{NOTA}-\mathrm{MAL}-\mathrm{FSH} 4$ with or without aprotinin in mice bearing tumors. 